\title{
Eco-dyeing of wool yarn with Ziziphus jujuba Mill. (Ber) and its colour fastness properties
}

\author{
Lizamoni Chungkrang* \\ Department of Textiles and Apparel Designing, Faculty of Community Science, Assam \\ Agricultural University, Jorhat-785013 (Assam), India \\ Ava Rani Phukan \\ Department of Textiles and Apparel Designing, Faculty of Community Science, Assam \\ Agricultural University, Jorhat-785013 (Assam), India

\section{Binita Kalita} \\ Department of Textiles and Apparel Designing, Faculty of Community Science, Assam \\ Agricultural University, Jorhat-785013 (Assam), India \\ *Corresponding author. E-mail: kutumlucy@gmail.com

\begin{abstract}
In search of eco-friendly processes for dyeing with natural dyes research has been focused on identification and standardization of natural dyes. Considering the growing importance of natural colourants all over the world, the present work was undertaken with on aim to study the colour fastness properties of wool yarn dyed with bark of Ziziphus jujuba Mill. (ber). The dyed wool samples had good to excellent colour fastness to washing, crocking perspiration and sunlight. Different shades of brown colour of rust, candy pink, biscuit brown, nut brown and light brown were obtained using different mordants. This type of eco-dyeing process may be helpful in increasing the variety of colours in the field of textiles.
\end{abstract}

Keywords: Biocompatible, Biodegradable, Eco-friendly, Natural dye, Synthetic dye

\section{Article Info}

DOI:10.31018/jans.v10i3.1804

Received: June 21, 2018

Revised: August 20, 2018

Accepted: August 24, 2018

\section{How to Cite}

Chungkrang, L. et al. (2018). Eco-dyeing of wool yarn with Ziziphus jujuba Mill. (Ber) and its colour fastness properties. Journal of Applied and Natural Science, 10(3): $1046-1052$

\section{INTRODUCTION}

Natural dyes are the traditional colouring matter used since ancient times. They are called natural dyes because of their major origin in plants. For thousands of years people all over the world followed the same basic techniques, using roots, stems, barks, leaves, hard woods, berries and flowers of various dye plants and tree, as well as from certain insects and shell fishes. These are multi component extracts of unknown concentrations out of which structure of only main component is determined (Singh and Parmer, 1998; Khan et al., 2005). The natural colouring substances are now developing trends for their use all over the world because of health and toxicity problems created by the synthetic dyes. The accidental discovery of synthetic dyes in the middle of $19^{\text {th }}$ Century led to the near abandonment of natural dyestuffs. Presently there is a great demand for the use of natural colours throughout the world. All this happened due to the excessive use of synthetic dyes which is estimated around 10 , 00,000 tones per annum (Gulrajani, 1999). Production of synthetic dyes involves many violent chemical reactions and the by- products formed have to be discharged in water or in the atmos- phere. The unbridled use of synthetic dye and the non-treatment of effluents contained in the waste waters of the dyeing process have led to horrendous results and a terrible load on the environment. Synthetic dyes are petroleum bi products and some of them have toxic/ carcinogenic amines that create skin allergies and hazardous to human health. They are non-biodegradable and are deposited on earth casing soil pollution. Government of Germany was the first to take initiative to put ban on azo-dyes for manufacturing, dyeing and importing textiles and other consumer goods dyed with these dyes from January 1, 1995 by the act of German Legislation (Consumer Goods Ordinance). Netherlands followed a ban with effect from August 1, 1996 on similar lines. European Union is likely to impose ban on these toxic dyes shortly. India has also banned the use of specific azo-dyes and under notification "sufficient legal teeth" had been given for taking panel action against those who use these dyes (Kapoor and Pushpangadan, 2001; Singh et al., 2006). Most of natural dyes have low affinity for textiles (cotton, wool and silk) and require the use of mordant. Mordants are generally metallic salts of aluminum, iron, chromium, copper and others, for ensuring the reasonable fastness of the colour to sunlight 
and washing. The study was aimed to optimize the dyeing conditions of the selected dye and to study the fastness properties of selected dye on wool yarn

\section{MATERIALS AND METHODS}

Selection of yarn: For the investigation, the pure wool (Plate 1) yarn of 23 count and 19 twist was collected from Ludhiana, India.

Selection of dye source: The bark of Ber (Ziziphus jujube Mill) locally known as Bogari (Plate 2) was selected as the dye source for dyeing of wool yarn. The dye materials were collected from Dhemaji District, Assam, India and the powder form of dye materials are given in (Plate 3 ).

Selection of mordants: The selected mordants used in the research works were Alum $\left(\mathrm{Al}_{2} \mathrm{SO}_{4}\right)$, stannous chloride $\left(\mathrm{SnCl}_{2}\right)$, copper sulphate (CuSO $-4)$ and ferrous sulphate $\left(\mathrm{FeSO}_{4}\right)$. Varying concentrations of mordant for alum 0.1, 0.2, 0.3, 0.4 and $0.5 \mathrm{~g} / 1 \mathrm{~g}$ of yarn and for other mordants 0.01 , $0.02,0.03,0.04$ and $0.05 \mathrm{~g} / 1 \mathrm{~g}$ of yarn were taken for optimization of mordant concentration.
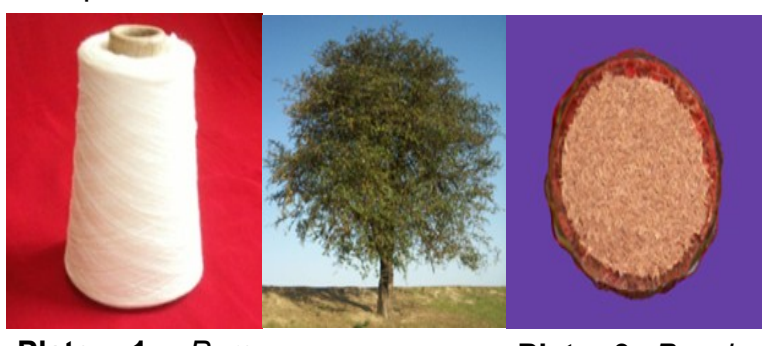

Plate 1. Pure Plate 2. Gen- Plate 3. Powder wool yarn. eral view of Z. form of Z. jujuba jujuba Mill plant. Mill plant.

\section{Chemicals}

used: The chemicals used for the study and their purposes are given below:

\begin{tabular}{lll}
\hline $\begin{array}{l}\text { Name of the } \\
\text { chemicals }\end{array}$ & $\begin{array}{l}\text { Molecular } \\
\text { formula }\end{array}$ & Purpose \\
\hline Sodium carbonate & $\mathrm{Na}_{2} \mathrm{CO}_{3}$ & Extraction \\
Sodium hydroxides & $\mathrm{NaOH}$ & Extraction \\
Acetic acid & $\mathrm{CH}_{3} \mathrm{COOH}$ & For colour fastness test \\
Sodium bicarbonate & $\mathrm{NaHCO}_{3}$ & For colour fastness test \\
Sodium chloride & $\mathrm{NaCl}_{2}$ & For colour fastness test \\
Urea & $\mathrm{Na}_{2} \mathrm{CONH}_{2}$ & For colour fastness test \\
\hline
\end{tabular}

Instruments used: The instruments used in the research work were as follows:

Spectrophotometer: It was used to measure the optical density of dye solutions.

Launder-o-meter: It was used for determining the washing fastness of dyes.

Crock-o-meter: It was used to determine the rubbing fastness of dyes.

Perspire-o-meter: It was used to determine the perspiration fastness of dyes.

Grey scale: It was used to determine the fastness grades of dyes.

Determination of dye absorption (\%): For determining the per cent dye absorption by the yarn, the dye solution before and after dyeing was subjected to visual light specific wavelength using spectrophotometer. A fixed concentration of dye solution was maintained. The absorbance of the solution was recorded before and after dyeing of the samples. The dye absorbance was calculated as given below:

Equation1. Percentage of absorption $=\mathrm{OD}$ of the dye liquor before dyeing - OD of the dye liquor after dyeing / OD of the dye liquor before dyeing $X$ 100

Dilution of dye solution: The maximum optical density was taken as 1 , above which the dye solutions had to be further diluted. The dilution of the samples was maintained as given below.

Dye solutions : $10 \mathrm{ml}$

Distilled water : $100 \mathrm{ml}$ for 10 times dilution (Phukan, 2004).

It was difficult to get maximum optical density value of dye solution obtained by optimized extraction procedure. Therefore, a suitably diluted dye solution was used to determine maximum optical density value. The dilution of which the optical density value was around 0.3 was selected as the suitable solution (Gohl and Vilensky, 1983).

Optimization of dyeing conditions: A series of experiments were conducted to determine the optimum values of eight variables, namely wavelength of light, method of dye extraction, dye extraction time, concentration of alkali, dye material concentration, dyeing time, mordant concentration and mordanting methods. In all the experiments, the values of the variables being optimized were kept constant for all other experiments (Table 1) based on some studies on natural dyes (Mahale et al., 2002; Shanker and Vankar, 2005). The conditions which were constant in all the experiments were as below:

Optimization of wavelength of light: For determining the optimum wavelength of light, diluted extracts were used as was difficult to get maximum optical density value of dye solution obtained by extraction procedure. The optical density value at different wavelengths starting from 400 $\mathrm{nm}$ to $600 \mathrm{~nm}$ (Trotman, 1994) was randomly noted by placing the 10 times diluted dye solution in spectrophotometer. After dilution of the dye solution the optical density at different wavelength was noted and the peak optical density was selected as optimum wavelength.

Optimum of dye extraction method: For determining the optimum method of dye extraction, the dyes were extracted by three different methods i.e., aqueous, acidic and alkaline. The method which gave maximum optical density was taken as optimum method of dye extraction.

Aqueous method: $1 \mathrm{~g}$ of dye material was boiled in $100 \mathrm{ml}$ of soft water at $100^{\circ} \mathrm{C}$ for 30 minutes. The extract was then filtered through a strainer and optical density was recorded.

Acidic method: $1 \%$ of acidic solution was pre- 
Chungkrang, L. et al. / J. Appl. \& Nat. Sci. 10 (3): 1046 -1052 (2018)

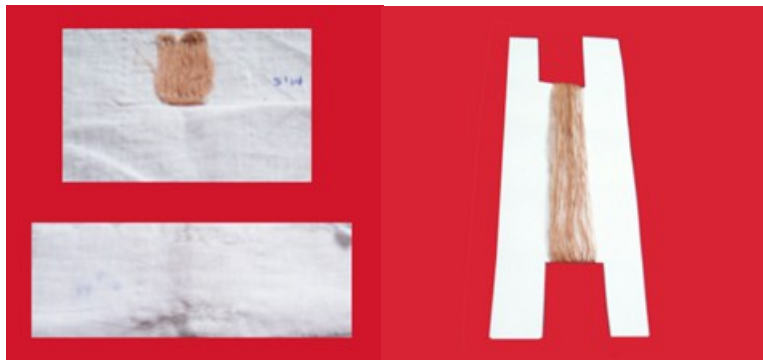

Plate 4. Sample for Plate 5. Sample for washing and perspira- crocking. tion.

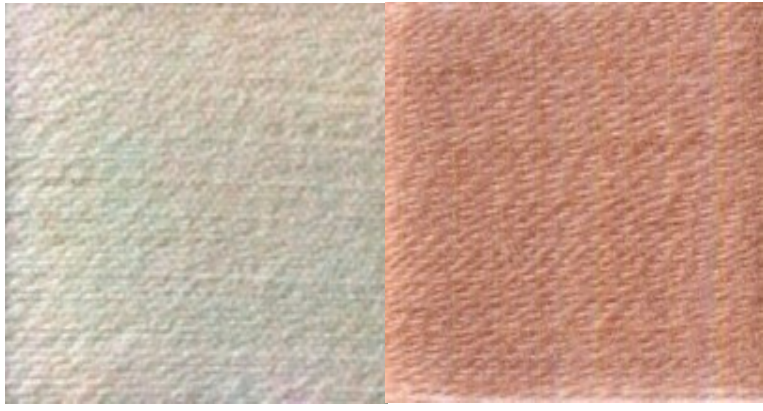

Original

Colour obtained: Off white

Without mordant

Colour obtained: Biscuit brown

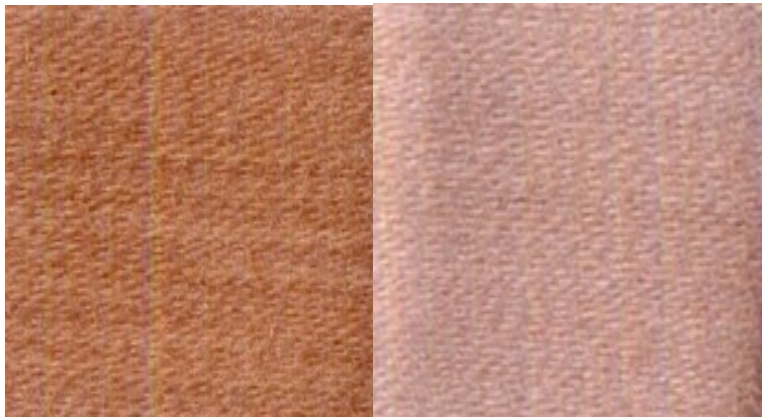

Alum

Colour obtained: Rust

Stannous chloride

Colour obtained: Light brown

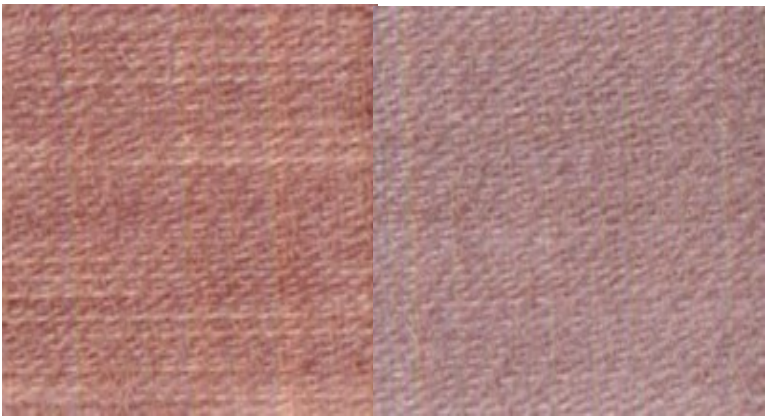

Copper sulphate Colour obtained: Candy pink

Ferrous sulphate

Colour obtained: Nut brown

Plate 6. Samples dyed with dye prepared from Ziziphus jujuba. pared by adding $1 \mathrm{ml}$ of $\mathrm{HCl}$ in $100 \mathrm{ml}$ of soft water. $1 \mathrm{~g}$ of dye material was then added and heated at $100^{\circ} \mathrm{C}$ for 30 minutes. Dye solution was then allowed to cool, filtered and the optical density of the dye solution was recorded.

Alkaline method: $1 \%$ alkaline solution was prepared by adding of $1 \mathrm{~g}$ sodium carbonate in $100 \mathrm{ml}$ of water. $1 \mathrm{~g}$ of dye material was then added and boiled at $100^{\circ} \mathrm{C}$ for 30 minutes. The dye extracts were the allowed to cool, filtered and the optical density of the dye extract was recorded.

Optimization of dye extraction time: For determining the optimum dye material extraction time, the optimized extraction method was done with the material liquor ratio (MLR) as 1: 100 . These solutions were then boiled for $30,45,60,75$ and 90 minutes. The maximum optical density value obtained was taken as the optimum time for extraction of dye.

Optimization of alkali concentration: For determination the optimum alkali concentration, six concentrations that is $0.1,0.3,0.5,0.7,0.9$ and $1 \mathrm{~g}$ were added separately along with $1 \mathrm{~g}$ of dye material in $100 \mathrm{ml}$ of water and boiled for optimum duration (minutes). The maximum optical density value of concentration of alkali was taken as the optimum concentration of alkali.

Optimization of dye material concentration: The optimum concentration of dye material was determined by varying quantities of dye material that is $1,2,3,4,5$ and $6 \mathrm{~g}$ were taken separately in six beakers containing $100 \mathrm{ml}$ of water and extracted for optimum duration. After extraction, the dye solutions were filtered through a strainer and optical density value of each solution were measured with the help of a spectrophotometer.

Six yarn samples of $1 \mathrm{~g}$ each were passed separately in these six dye baths and the dyeing was carried out $60-70^{\circ} \mathrm{C}$ for 30 minutes with occasional stirring. Then the samples were taken out from the dye baths and the optical density value of each dye solutions was measured. The percentage dye absorption by each sample at different dye material concentrations was calculated. The maximum dye absorption obtained was taken as optimum dye material concentration.

Optimization of dyeing time: For determining the optimum dyeing time, optimum concentration of dye material was boiled for optimum duration to extract the dye. After extraction the liquors were strained. The presoaked wool samples were added separately in each dye bath and dyed for different timings that were $30,45,60$ and 90 minutes at $60-70^{\circ} \mathrm{C}$. Then the optical density value of dye solution before and after dyeing at different dyeing times were recorded with the help of the spectrophotometer and the per cent of dye absorption by each sample at different dyeing times were calculated. The dyeing time was then optimized from the maximum per cent of dye absorption.

Optimization of mordant concentration: Varying 
concentrations of mordant for alum $0.1,0.2,0.3$, 0.4 and $0.5 \mathrm{~g} / 1 \mathrm{~g}$ of yarn and for other mordants $0.01,0.02,0.03,0.04$ and $0.05 \mathrm{~g} / 1 \mathrm{~g}$ of yarn were taken for optimization of mordant concentration. The different concentrations giving the maximum dye absorption were taken as optimum mordant concentration.

Optimization of mordanting method: For determining the optimum mordanting method for alum, stannous chloride, copper sulphate and ferrous sulphate, dyeing was carried out with three different mordanting methods i.e., pre simultaneous and post mordanting. The maximum dye absorption obtained was selected as the optimum obtained was selected as the optimum method of mordanting (Gohl and Vilensky, 1983; Anderson, 1974).

Evaluation of dyed samples: The samples of dyed wool yarn were evaluated for their different colour fastness and physical properties by the following methods.

Determination of fastness properties of dyed samples: Colour fastness depends upon many factors such as type of dye, dyeing time, dyeing temperature and other various factors (Mahale et al., 2002). All the dyed yarn samples were evaluated for colour fastness to washing, rubbing (dry and wet), perspiration and light by the standard procedure.

Colour fastness to washing (ASTM standard, 1968): For preparing a composite specimen, two fabric pieces each measuring $10 \mathrm{~cm} \times 4 \mathrm{~cm}$ were taken. One of the fabric pieces taken was woolen or silken and the other one was cotton. The dyed yarn to be tested was placed between these two pieces (in parallel lengths), the amount of yarn being approximately half of the combined weight of adjacent fabrics. The sample was sewn on all

\begin{tabular}{ll}
\hline Grade & Fastness \\
\hline 5 & Excellent \\
4 & Good \\
3 & Fair \\
2 & Poor \\
1 & Very poor \\
\hline
\end{tabular}

the four sides.

All the composite specimens prepared as above were weighed and the required quantity of soap

\begin{tabular}{ll}
\hline Grade & Staining \\
\hline 5 & Negligible or no staining \\
4 & Slightly stained \\
3 & Noticeably stained \\
2 & Considerably stained \\
1 & Heavily stained \\
\hline
\end{tabular}

solution of $2 \mathrm{~g} /$ litre of water was prepared for keeping the material liquor ratio of 1: 50 . One composite specimen was placed in each of the eight containers of a launder-o-meter along with 10 steel balls and soap solution previously heated to $40 \pm 2^{\circ} \mathrm{C}$ was added to it. The composite specimens were treated for 30 minutes at $40 \pm 2^{\circ} \mathrm{C}$ in

the launder-o-meter. The composite specimens were removed and rinsed in cold water. The samples were squeezed and the stitching along two long sides and one short side was removed. The composite samples were opened and dried in air temperature at exceeding $60^{\circ} \mathrm{C}$ (Plate 4).

Colour fastness to rubbing or crocking (ASTM standard, 1968): For testing fastness to dry rubbing a test specimen was prepared, in form of a layer of parallel strands of yarn by wrapping it lengthwise on a rectangular cardboard of size 14 $\mathrm{cm} \times 5 \mathrm{~cm}$. The undyed cotton sample of size $5 \times$ $5 \mathrm{~cm}$ was fixed to the finger of rubbing device of crock-o-meter and test specimen was fixed at the base of the rubbing device. The test specimen was rubbed to and fro with undyed pieces with a downward force of $900 \mathrm{gm}$ in a straight line along a track of $10 \mathrm{~cm}$ for 10 times in 10 seconds. The test specimen was then graded for the change in colour and staining using a grey scale. The test was carried out similarly for fastness to wet rub-

\begin{tabular}{ll}
\hline Grade & Fastness \\
\hline 8 & Outstanding \\
7 & Excellent \\
6 & Very good \\
5 & Good \\
4 & Fairly good \\
3 & Fair \\
2 & Poor \\
1 & Very poor \\
\hline
\end{tabular}

bing (Plate 5).

Colour fastness to perspiration (ASTM standard, 1968)

Preparation of acidic and alkaline test solution: The acidic test liquor was prepared by dissolving $2.65 \mathrm{~g}$ of sodium chloride and $0.75 \mathrm{~g}$ of urea/litre and adjusting the $\mathrm{pH}$ of the solution to 5.6 with addition of acetic acid. The alkaline test liquor was prepared by dissolving $3 \mathrm{~g}$ of sodium chloride/litre and adjusting the $\mathrm{pH}$ of the solution

Table 1. Constant values of dyeing conditions.

\begin{tabular}{ll}
\hline Conditions & Constant values \\
\hline Material liquor ratio (Dyeing) & $1: 30$ \\
Dye extraction temperature & $100^{\circ} \mathrm{C}$ \\
Dyeing temperature & $60^{\circ} \mathrm{C}-70^{\circ} \mathrm{C}$ \\
Mordanting time & 30 \\
\hline
\end{tabular}

Table 2. Summary of optimum dyeing conditions.

\begin{tabular}{lc}
\hline Conditions & Optimum value \\
\hline Wavelength (nm) & 480 \\
Method of dye extraction & Alkaline \\
Dye extraction time (min) & 60 \\
Alkali concentration (gm) & 0.5 \\
Dye material conc. (gm) & 3.0 \\
Dyeing time (mins) & 45 \\
Mordant conc. (g) and mordanting methods \\
Alum (Sim) & 0.5 \\
Stannous chloride (Post) & 0.03 \\
Copper sulphate (Post) & 0.01 \\
Ferrous sulphate (Sims) & 0.03 \\
\hline
\end{tabular}


Chungkrang, L. et al. / J. Appl. \& Nat. Sci. 10 (3): 1046 -1052 (2018)

Table 3. Ratings for colour fastness properties of dyed samples.

\begin{tabular}{|c|c|c|c|c|c|c|c|c|c|c|c|c|c|}
\hline \multirow{4}{*}{$\begin{array}{l}\text { S. } \\
\text { N. }\end{array}$} & \multirow[t]{4}{*}{ Mordant used } & \multirow{4}{*}{$\begin{array}{l}\text { Mordant- } \\
\text { ing } \\
\text { method }\end{array}$} & \multirow{4}{*}{$\begin{array}{l}\text { Sun- } \\
\text { light }\end{array}$} & \multicolumn{10}{|c|}{ Fastness properties } \\
\hline & & & & \multirow{2}{*}{\multicolumn{2}{|c|}{ Washing }} & \multicolumn{4}{|c|}{ Crocking } & \multicolumn{4}{|c|}{ Perspiration } \\
\hline & & & & & & \multicolumn{2}{|c|}{ Dry } & \multicolumn{2}{|c|}{ Wet } & \multicolumn{2}{|c|}{ Acidic } & \multicolumn{2}{|c|}{ Alkaline } \\
\hline & & & & $\mathbf{C C}$ & CS & CC & CS & CC & CS & CC & CS & CC & CS \\
\hline 1. & Without mordant & - & 6 & $4-5$ & 5 & 5 & 5 & $4-5$ & 4 & 5 & 5 & $\overline{4-5}$ & $4-5$ \\
\hline 2. & Alum & Sim & 7 & $4-5$ & 5 & 5 & $4-5$ & $4-5$ & $3-4$ & $4-5$ & 4 & $4-5$ & $4-5$ \\
\hline 3. & Stannous chloride & Post & 6 & 5 & 5 & 5 & $4-5$ & 5 & $4-5$ & $4-5$ & $4-5$ & 5 & 5 \\
\hline 4. & Copper sulphate & Post & 6 & 5 & 5 & 5 & 5 & 5 & 5 & 5 & 5 & 5 & 5 \\
\hline 5. & Ferrous sulphate & Pre & 7 & 5 & 5 & 5 & 5 & $4-5$ & $4-5$ & 5 & 5 & 5 & 5 \\
\hline
\end{tabular}

CC: Colour change; CS: Colour staining; Pre: Pre-mordanting; Sim: Simultaneous mordanting; Post: Post mordanting

to 7.2 with the addition of sodium bicarbonate.

A composite specimen was prepared by placing the test specimen of size $5 \mathrm{~cm} \times 4 \mathrm{~cm}$ between the two adjacent fabrics of size of $5 \mathrm{~cm} \times 5 \mathrm{~cm}$, one being wool or silk and the other being cotton. The test specimen was stitched along all the four sides. The test specimens were soaked in the acidic and alkaline test solutions are prepared above separately with material to liquor ratio 1: 50 for 30 minutes at room temperature. Then the treated samples were kept between two glass plates of perspire-o-meter under a force of $500 \mathrm{~g}$. The apparatus was kept in hot air oven for four hours at $37 \pm 2^{\circ} \mathrm{C}$. Then the test samples were removed from the oven and air dried with temperature not exceeding $60^{\circ} \mathrm{C}$. The numerical grading for colour change of the test pieces and for staining of two adjacent pieces was done using a grey scale (Plate 4).

Standards for colour fastness: Colour fastness to all the procedure except light were evaluated in terms of colour change and colour staining. These were expressed by grading the sample 1-5 using Grey Scale. The samples were evaluated for colour change. A piece of original dyed yarn and the

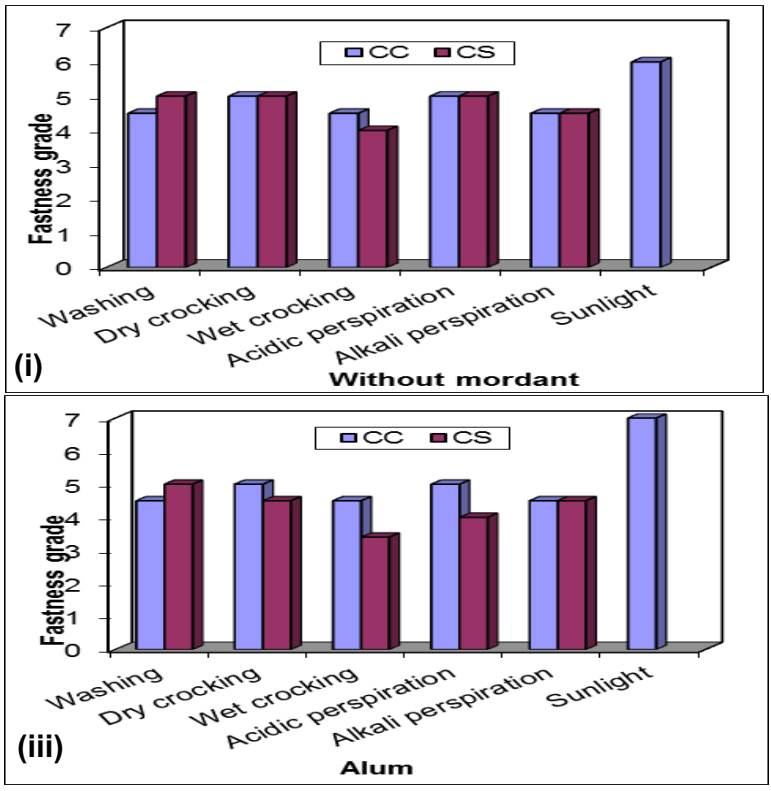

test specimen were placed side by side in the same plane. The visual difference between the original and test specimen was compared and fastness grade was given with the help of a grey scale for assessing change in colour. The fastness grade given was that number of the grey scale which corresponded to the contrast between the original and washed specimen.

The different grade of grey scale indicated the level of fastness as mentioned below:

Further the numeric rating of staining of fabrics was judged as follows by employing the grey scale for assessing staining.

Colour fastness to sunlight (ASTM standard, 1968): The yarn to be tested was wrapped in par-
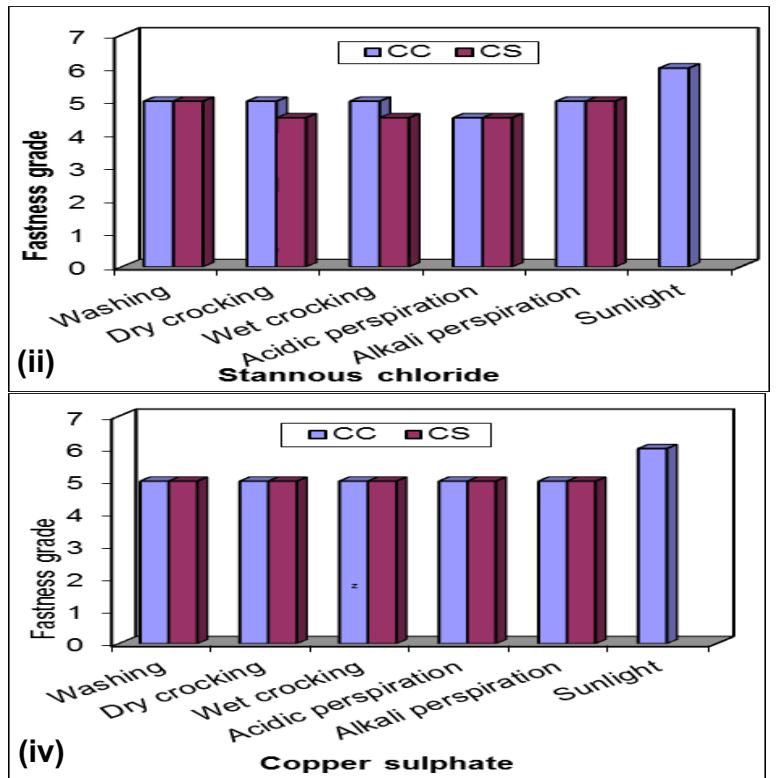

(iv)

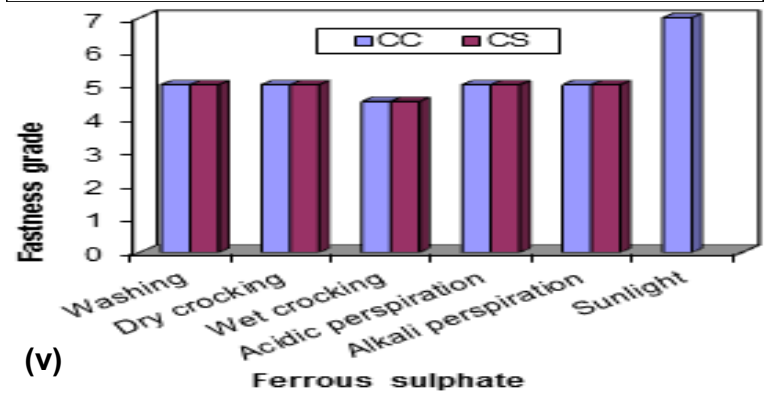

Fig. 1 (i- v). Ratings for colour fastness properties of dyed samples. 
allel lengths closely on a card to make a test specimen of area not less than $1 \mathrm{~cm} \times 6 \mathrm{~cm}$ taking care that all knots present in the yarn while preparing the test specimen were under the back of the card. The test specimens and the standard patterns were mounted in an exposure rack in such a way that half of each specimen was covered and other half was exposed to light.

The samples were exposed to day light every day from sunrise to sunset, along with the standard patterns, keeping the exposure rack at an angle of $45^{\circ}$ and to face the north east direction. When change in colour could just be perceived, the number of standard patterns showing a similar change was noted. For evaluating the light fastness in full, test specimens were exposed further, the total exposure being 40 hours. The change in colour of the test specimens was compared with the change which had occurred in standard patterns. The light fastness of specimen was the number of the standard pattern which showed similar change in colour. If the specimen showed the colour change approximately half way between two standards approximately half grade was given.

The different grades in the case of light fastness indicated the following level of fastness:

Determination of fastness properties of dyed samples: Fastness properties of washing, rubbing or crocking, sunlight and perspiration of dyed samples were determined by the procedure prescribed by ASTM standard (1968).

\section{RESULTS AND DISCUSSION}

Dyeing experiments were carried out using natural dyes on three different materials such as yarn, fabric and paper and it was observed that red and red tones were obtained from materials dyed with madder, soil color from materials dyed with walnut, yellow and yellow tones from materials dyed with weld, blue and blue tones from materials dyed with indigo and finally green and green tones from materials dyed with weld-indigo. It was also observed in dyeing experiments conducted that weld, from which light color tones are obtained, had the best values in terms of light and rubbing fastnesses (Dogan and Akan, 2018). According to $\mathrm{MIAH}$ et al. (2016) dye extracted from onion's outer shell can be successfully used for dyeing of wool to obtain a wide range of soft, pastel and light colors by using metallic mordants. With regards to colorfastness test samples exhibited excellent fastness to washing (except pre and post mordanting), excellent fastness to rubbing (except pre, simultaneous and post mordanting- Potassium dichromate). Barani and Rahimpour (2014) stated that the dyeing conditions of wool fibers with Prangos ferulacea natural dye were optimized by response surface methodology (RSM). The dyeing temperature with and without mordant increased the color strength value of dyed samples. In addition, an increase in the dyeing time and mordant concentrations leads to higher color strength value. Plasma pretreatment of wool fiber results in altering the surface of the wool fiber and enhances Prangos ferulacea dye uptake of wool fibers. The presence of mordant in the dyeing wool fiber with Prangos ferulacea improves its fastness properties. Phukan (2014) also studied wool yarn dyeing with four different plant sources namely Myrica nagi Thumb, Garcinia xanthochymus Hook. f., Artocarpus integrifolia Linn. $f$. and Eugenia jambolana Lam. and the fastness grades of the dyed wool yarns were rated as good. Absolutely no colour change was found in dry rubbing samples. However, very little staining was found in few samples. Light fastness was also found to be good in all the dyed samples. As regards to washing and perspiration fastness, all the samples showed a negligible change.

In the study, the dyeing conditions for wavelength, method of dye extraction, dye extraction time, alkali concentration, dye material concentration, dyeing time, mordant concentration and mordanting method were optimized and are given in Table 2.

Different shades of colours were produced after dyeing of wool yarn with the bark of Ziziphus jujuba Mill. The dye was rust, candy pink, biscuit brown, nut brown, light brown and are given in Plate 6. Similar study has been carried out by Shanker et al. (2004) on dyeing of wool with Partulaca flower extracts using metal mordants and found different shades of colour like orange, brick red, brick brown, dull brown, green, brown etc. The colour fastness grades for the samples dyed under optimum dyeing conditions, using different mordants were compared with that of controlled samples and are presented in Fig. 1 (i-v) and Table 3. Samples were evaluated for colour fastness to sunlight, washing, crocking (dry and wet) and perspiration (acidic and alkaline) by the standard procedures and the effect were rated with the help of the International Gray Scales.

The values of light fastness Figure $1(\mathrm{i}-\mathrm{v})$ and Table 3 indicate that wool samples dyed with bark of Ziziphus jujuba Mill. dye using alum and ferrous sulphate had good light fastness (7) while, without mordant, stannous chloride and copper sulphate mordanted samples have fair fastness to light (6). The overall all light fastness was fair to good. Similar results have also been found by Rani and Singh (2004) in the case of Indian blackberry dye. The wash fastness value of different samples is given in Table 3. These results indicate that all the samples (without mordant, alum, stannous, copper and ferrous sulphate) dyed with different mordants have good to very good wash fastness (4-5, 5). The data also indicates that there were a negligible colour change on samples of without mor- 
dant and alum. The dyed wool samples were tested for colour fastness to crocking and the results are given in Figure 1 (i-v) and Table 3. Copper sulphate sample showed very good (5) colour fastness in both dry and wet crocking. The colour fastness to crocking was also good to very good in samples treated with stannous chloride and ferrous sulphate. The sample without mordant and mordant with alum showed poor colour fastness in wet crocking.

Colour fastness to perspiration ratings of the dyed and mordanted samples showed that all the samples except sample dyed with alum exhibits negligible colour change and colour staining in both of acidic and alkaline conditions and others have good to excellent fastness properties to perspiration. Tomer and Singh (2004) have also studied dying of wool with the leaves of Banyan (Ficus bengalensis) tree. A wide range of shades ranging from candy rose to rose pink, light copper to leaf brown and brownish mushroom to dark grayish green were produced depending on the choice of mordants and different concentration of mordants. Colours obtained had good rubbing properties and light fastness.

\section{Conclusion}

Most of the samples dyed with Z. jujuba Mill plant had good to excellent colour fastness properties against the washing, crocking, perspiration and sunlight. Different shades of brown colour like rust, candy pink, biscuit brown, nut brown and light brown were obtained with different mordents. This type of eco-dyeing process increases the variety of colours in the field of textiles. The study will be helpful in the field of textiles as well as artisan and craftsman's who are involved in natural products. Since the plant source $Z$. jujuba Mill plant (ber) is abundantly available in North-East region, the interested youth can open up an enterprise by selling dye in powder form which will be sustainable and economically viable.

\section{REFERENCES}

1. Anderson, B. (1971). Creative spinning, weaving and plant dyeing. Angus and Robertson Ltd., Singapore. pp. 24-28.

2. ASTM (1968). Standard test methods for breaking load (strength) and elongation of yarn by single strand methods. Part. 24, American Society for Testing Material, Philadelphia. pp. 444-450.

3. Barani, H. and Rahimpour, S. (2014). The Dyeing
Procedures Evaluation of Wool Fibers with Prangos ferulacea and Fastness Characteristics. Advances in Materials Science and Engineering. Hindawi Publishing Corporation. pp. 1-7.

4. Dogan, S.D. and Akan, M. (2018). A Research on Colours and Fastness Values of Different Materials Dyed with Some Natural Dyes. International Journal of Materials Science and Applications. 7(3): 69-74.

5. Gohl, E.P.G. and Vilensky, L.D. (1983). Textile Science: $2^{\text {nd }}$ edn. Longman Cheshire Pvt. Ltd., Australia. pp. 147.

6. Gulrajani, M.L. (1999). Present status of natural dyes. Colourage, 46 (7): 19-28.

7. Kapoor, V.P. and Pushpangadan, P. (2001). Use of natural dyes in preparation of Herbal-Gulals. In conventional proceedings natural dyes. Department of Textile Technology, December 17-18, IIT, Delhi. pp. 17-19.

8. Khan, M.A.; Khan, M.; Srivastava, P.K. and Mohammad, F. (2005). Extraction of natural dyes from Myrobalan, Gallnut and Pomegranate and their application on wool. Colourage, LII (12): 53-59.

9. Mahale, G.; Sunanada, R.K. and Sakshi, S. (2002). Coour fastness of eco dyed cotton with marigold. Tex. Trends, XLIV (10): 35-36.

10.MIAH, M. R; Telegin, F.Y. and Rahman, M. S. (2016). Eco-friendly dyeing of wool fabric using natural dye extracted from onion's outer shell by using water and organic solvents. International Research Journal of Engineering and Technology (IRJET). 3 (9): 1-18.

11.Phukan, R. (2004). Yarn dyeing with natural dyes extracted from plant sources. Unpublished Ph. D Thesis, Gauhati University, Guwahati, Assam.

12.Phukan, R. (2014).Yarn dyeing with natural dyes extracted from plant sources. Asian Journal of Home Science (AJHS). 9 (1): 215-218.

13.Shanker, R. and Vankar, P.S. (2005). Ultrasonic energized dyeing of wool with mirabilis jalpa flowers. Colourage, LII (2): 57-61.

14.Shanker, R.; Shivani and Vankar, P.S. (2004). UItraenergised dyeing of wool with Portulaca flower extracts using metal mordants. Colourage, LI (10): 41-46.

15.Rani, A. and Singh, O.P. (2004). Dyeing of polyster with Indian blackberry dye. Colourage, LI (3): 21-27.

16.Singh, K. and Parmar, S.S. (1998). Are natural dyes safer than synthetic dyes? Tex. Trends, XL (11): 2327.

17.Singh, O.P.; Bains, S. and Goraya, G. (2006). Dyeing of wool with Arjun (Arjuna terninella) dye. Tex. Trends, XLVIX (6): 29-31.

18.Tomer, P. and Singh, S.S.J. (2004). Utilization of Banyan (Ficus bengalensis) leaves for wool dyeing. Tex. Trends, XLVI (11): 25-29.

19.Trotman, E.R. (1994). Dyeing and Chemical Technology of Textiles Fibres. Sixth Edn., Griffin and Co., London, pp. 99, 373-383, 68-469. 